\title{
Phosphoserine Motif
}

National Cancer Institute

\section{Source}

National Cancer Institute. Phosphoserine Motif. NCI Thesaurus. Code C13977.

A protein motif containing a phosphorylated serine residue. These motifs can influence both protein-protein interactions and cellular signaling. 